\title{
Oil and gas infrastructure decommissioning in marine protected areas: system complexity, analysis and challenges
}

\author{
Burdon, D. , Barnard, S., Boyes, S.J. \& Elliott, M. \\ Institute of Estuarine \& Coastal Studies, University of Hull, Hull, UK HU6 7RX \\ *Corresponding author: Daryl Burdon, D.Burdon@hull.ac.uk; Tel. +44 1482466786
}

\begin{abstract}
:
Many offshore oil and gas production facilities are nearing the end of their operational life, with decommissioning now becoming a global challenge. The compatibility of decommissioning operations to marine protected areas (MPAs) creates further challenges. The recently-developed DAPSI(W)R(M) problem structuring framework (covering Drivers, Activities, Pressures, State changes, Impacts (on Welfare) and Responses (as Measures)) was applied here to interrogate the complexity of decommissioning oil and gas infrastructure within MPAs, with outputs feeding into the development of a novel database tool for Screening Potential Impacts of Decommissioning Activities (SPIDA). In meeting the current requirements of the marine regulatory regime, SPIDA provides a more streamlined, evidence-based process which can be applied by industry, statutory nature conservation bodies and regulators for identifying and evaluating evidence that supports the implications of decommissioning alternatives on the condition of MPAs. SPIDA has been developed to be adapted for other activities and sectors, including offshore renewables.
\end{abstract}

\section{Keywords:}

DAPSI(W)R(M); decision support framework; SPIDA tool; ecosystem services; marine policy; 10-tenets

\section{Introduction}

Our coasts and oceans have historically provided society with food, aggregates for building materials, fossil fuels for energy generation, global transport routes, a place to observe and study nature and participate in recreational activities, and more recently a valuable source of renewable energy in the form of wind, tidal and wave energy. In marine management, it has been suggested that there is only one big idea: how to maintain and protect ecological structure and functioning while at the same time allowing the system to produce ecosystem services from which we derive societal goods and benefits (Elliott, 2011). This is reflected in marine policy, for example the UK Marine Policy Statement provides a shared vision for its devolved governments of 'clean, healthy, safe, productive and biologically diverse oceans and seas' (HM Government, 2011). Such a vision is consistent with the ecosystem approach as advocated by the Convention on Biological Diversity (CBD, 2000), where the environment, economy and society are all considered in an integrated way. Given that human activities along coastlines can be intense, and are increasing and extending further offshore, understanding the impacts on the natural environment and their impact on the economy and society is of paramount importance (Atkins et al., 2011). 
The energy generation sector has shown a shift in focus from non-renewable sources, such as oil and gas, to renewables including wave, tidal and wind energy. This is reflected in the Europe Union's adopted collective renewable energy generation target of $20 \%$ by 2020 (Renewables Directive 2009/28/EC Annex 1) and as such offshore wind energy has been a growing industry over the last two decades (Smyth et al., 2015). Many offshore oil and gas production facilities which have been operating globally since the 1960s are nearing the end of their operational life. Therefore, the next 30 years will see a major decommissioning of these facilities which is becoming a worldwide challenge (Chandler et al., 2017; Rouse et al., 2017). For example, in the North Sea it is forecast that 349 fields across the UK, Norwegian, Danish and Dutch continental shelves will require decommissioning between 2017 and 2025, comprising almost 2,500 wells, 200 platforms and 7,500 km of pipelines (Oil and Gas UK, 2017). Most of this infrastructure is within the UK continental shelf ( 214 fields, 1,624 wells, 98 platforms and 5,514 km of pipelines) and current forecasts suggest that decommissioning this UK infrastructure will cost $£ 17$ billion between 2017 and 2025 (Oil and Gas UK, 2017).

There are considerable scientific uncertainties in the overall impacts of decommissioning, and the UK governmental guidance (from BEIS, the Department of Business, Enterprise, Industry and Skills) for comparative assessments requires that the chosen approach must demonstrate an understanding of five main criteria. These comprise elements of safety, environmental, societal, technological and economic impacts, not least because the taxpayer carries the major burden of decommissioning costs (BEIS, 2018). These criteria, broken down into sub-criteria, are used to assess the options for decommissioning oil and gas structures, which include complete removal to land, partial removal to land, leaving wholly in place, re-use and disposal at sea (BEIS, 2018).

The NE Atlantic protocol from the Oslo and Paris Commission (OSPAR 98/3) requires installations to be removed unless certain derogation criteria can be met. Derogation cases under OSPAR 98/3 are further discussed below. In contrast, several regimes globally are questioning the appropriateness of removing structures at the end of their lives, as under both economic and environmental interests, there are arguments for leaving certain structures in place. Following the 'rigs to reefs' project in the Gulf of Mexico (Reggio, 1987; Schroeder \& Love, 2004; Kaiser \& Pulsipher, 2005), there is increasing academic discussion regarding the merits of removing or leaving in place these structures and the effects of these options on the adjacent marine features.

There is an increasing need to protect the marine environment from anthropogenic activities, with a range of Marine Protected Areas (MPAs) established globally, with the primary aim to spatially identify and conserve biodiversity across connected ecological networks, including rare, threatened and endangered habitats and species (Saunders et al., 2015). There is a wide range of ecosystem services and societal goods and benefits that are also provided by MPAs (Fletcher et al., 2012; Potts et al., 2014; Burdon et al., 2017) and thus the sustainable delivery of these valuable services may potentially be at risk by decommissioning activities. Many MPAs were designated after oil and gas exploration and operation, for example within UK waters, 13 MPAs have oil and gas installations (or installations and pipelines) within them, whilst a further 33 MPAs have oil and gas pipelines running through them ${ }^{1}$. Hence it is possible that such MPA sites are in environmental equilibria with the structures in place and so it is hypothesised that removal could disturb that equilibrium. Despite this, the effects of

\footnotetext{
${ }^{1}$ Based on the overlap of offshore and gas surface installations and pipelines within MPAs in UK waters, derived from Oil and Gas UK data and MPA boundary data as at July 2017.
} 
decommissioning activities within MPAs are relatively unknown due to a lack of sufficient scientific evidence in assessing and demonstrating long-term and cumulative impacts on MPA conservation objectives and site integrity. This introduces considerable challenges for all involved in decommissioning: for industry to fulfil their environmental obligations, for regulators to use risk-based procedures for assessing effects in consenting operations, and for Statutory Nature Conservation Bodies (SNCBs) as consultees in the approvals process. A robust evidence-based approach is therefore needed to improve and bring innovation to the decision-making process, and to make the assessment of effects of decommissioning on MPAs more consistent, efficient and transparent.

MPAs are designated according to a set of conservation features which may be species and/or habitats and the onus is on marine developers to demonstrate that their activities (covering construction, operation and decommissioning) will not adversely affect the integrity of those features. In essence, objectives for those conservation features have to be set and rigorously monitored. Decommissioning includes not only the removal of structures but also the introduction of them (albeit on a temporary basis, e.g. jack-up rigs), and by definition represents a 'plan or project' with a potential to prevent the conservation objectives being reached. However, whilst there are a number of decision support tools which have been developed and applied to oil and gas decommissioning and/or MPA designation and management, there is no suitable decision support tool available to specifically assess the impacts of decommissioning activities on the natural marine environment within MPAs or to set such assessment within the wider context of the ecosystem services and goods and benefits provided for society.

For example, in Southern California, Bernstein (2015) developed a conceptual framework to identify potential decommissioning options for oil and gas infrastructure based on legal requirements, environmental/ecological impacts, feasibility, liability and costs. For the same location, Henrion et al. (2015) developed a decision analysis software tool ('PLATFORM') to clarify and evaluate decision strategies against a comprehensive set of objectives which also included economic viability, technological feasibility, and social acceptability. With respect to MPAs, PRISM (PRoducing Information from Sensitivity Matrices), PISA (Potential Impacts from Selected Activities) and STARFISH (Simplified Tables for Assessing the need for Regulation, using Filtered Impacts on Species and Habitats) were tools developed by the second author here specifically to support stakeholder engagement workshops for the UK Net Gain Marine Conservation Zone (MCZ) Project (Net Gain, 2011). The concept behind these MPA-focussed tools has since been further developed, for example to produce tools such as FEAST (FEature Activity Sensitivity Tool) which is currently used by Marine Scotland for determining potential management requirements for Nature Conservation MPAs (Marine Scotland, 2018). However, none of these also address the wider ecosystem services and goods and benefits which MPA features provide.

This paper details the development of a decision support framework and innovative evidence-based database tool to quantify the risks, opportunities and impacts (both positive and negative) of decommissioning on marine features, especially as they relate to designated features within MPAs. The framework presented here is then interrogated to enhance tools used to date by the regulator, industry and SNCBs. The framework aims to further increase the transparency of the decommissioning process within MPAs by enhancing the operability of the existing tools within an integrated database tool. While the initial focus of the decision support framework and associated database tool is on oil and gas decommissioning in MPAs, it has been developed with an in-built flexibility to evolve, and as 
such could be adapted for other activities and sectors, including offshore renewable energy developments.

\section{Decision Support Framework}

Following initial discussions with the regulator, industry, SNCBs, consultants and academics, a list of eight questions was generated to select a decommissioning strategy within an MPA, and these formed the basis of the decision support framework:

1) What oil and gas structure(s) require(s) decommissioning?

2) What are the potential decommissioning approaches for the structure?

3) What potential decommissioning activities are required?

4) What pressures are likely to result from decommissioning activities?

5) What MPA features are present within the site?

6) What is the potential loss or damage to the designated features?

7) What is the potential for the loss or gain of ecosystem services?

8) What is the potential for the loss or gain of societal goods/benefits?

The DAPSI(W)R(M) framework was employed as a problem structuring method to provide a logical framework within which to structure these questions (Elliott et al., 2017). This framework is a refinement of the much-used DPSIR framework (Patricio et al., 2016). It recognises that Drivers of basic human needs require Activities. These Activities result in Pressures, which are the mechanisms of State change of the natural environment and Impacts on human Welfare. These in turn require management Responses (defined as Measures), which can be used as feedback loops to address the Drivers, Activities, or Pressures identified within the system. Marine management usually assesses the State changes and Impacts on human Welfare but it controls the Drivers, Activities and Pressures. A summary of the DAPSI(W)R(M) components with specific relation to environmental impact of oil and gas decommissioning is presented in Table 1; each component is further discussed below.

\section{Insert Table 1 here}

Using the DAPSI(W)R(M) framework to provide the structure of the decision support framework, the questions were organised in a transparent, simple and logical sequence, aligned with the associated resources required to address the questions of interest (Figure 1). This process can be followed by the regulator, industry, SNCBs, consultants and academics to identify the sensitivity of marine features to decommissioning activities. The proposed framework enables the users to work through the questions sequentially and therefore simplifies the process. In order to address the eight specific questions relating to decommissioning, a range of data and information resources was identified (Figure 1). The seven resources identified were: those which exist and are deemed fit for purpose for this study (\#1); those which exist but require some refinement for the specific application in this study (\#2), and/or those which were not previously available and were therefore generated specifically for this study (\#3). The resources used are described below.

\section{Insert Figure 1 here}

It is important to emphasise from the outset the scope of the decision support framework and also what the decision support framework has not been designed to address (Table 2). 


\section{Insert Table 2 here}

\section{3. $\mathrm{DAPSI}(\mathrm{W}) \mathrm{R}(\mathrm{M})$ as a problem structuring method}

The DAPSI(W)R(M) framework accommodates the complexity of decommissioning oil and gas infrastructures within MPAs. This section expands on Table 1 to illustrate the complexity associated with each element of the framework.

\section{Drivers}

The extent to which offshore installations must be removed is determined by international law, regional policy drivers and the regulating authority of the national government on a case-by-case basis, hence there is a paramount legal Driver. The regulating authority must approve the decommissioning plans of the oil and gas operator to ensure compliance with legislation. To mitigate the environmental consequences of the industry, European Regional Seas conventions such as the Convention for the Protection of the Marine Environment of the North-East Atlantic (OSPAR Convention), the Barcelona Convention and its Protocols protecting the Mediterranean Sea, and the Convention on the Protection of the Marine Environment of the Baltic Sea Area (HELCOM) have all adopted recommendations for actions in relation to the regulation of offshore industries. For example, HELCOM Recommendation 14/9 relates to the Removal of Abandoned and Disused Offshore Units and recommends that 'the Governments of the Contracting Parties to the Helsinki Convention ensure that abandoned, disused offshore units and accidentally wrecked offshore units are entirely removed and brought ashore under the responsibility of the owner and that disused drilling wells are plugged' (HELCOM, 1993). Similarly, Ministers of the OSPAR signatory countries adopted a binding Decision (OSPAR Decision 98/3) to ban the disposal of offshore installations at sea, although the removal of pipelines is not covered by the Decision (OSPAR, 1998). Since this came into force, the dumping and leaving wholly or partly in place, of disused offshore installations is prohibited within the OSPAR maritime area. However, following assessment, the competent authority of the relevant Contracting Party may give a derogation, i.e. permission to leave installations or parts of installations in place if sufficient justification has been made. A derogation to the OSPAR 98/3 rule may be granted for:

- $\quad$ steel installations weighing $>10,000$ tonnes in air and placed before $9^{\text {th }}$ February 1999 ;

- gravity based concrete installations;

- floating concrete installations;

- any concrete anchor-base which results, or is likely to result, in interference with other legitimate uses of the sea.

The OSPAR 98/3 Decision is reviewed by the OSPAR Commission at regular intervals, to consider in the light of experience and technical developments whether the derogations from the general ban on dumping continue to be appropriate. The 2008 and 2013 policy reviews concluded that operational experience is insufficient to justify changing the derogation criteria. The next review is due in 2018. National regulating authorities must follow these international agreements in the management of oil and gas decommissioning applications with national legislation implementing these policies. Therefore, the driver for many countries within Europe is a 'clean seabed policy' and so any management framework has to be directed towards achieving this aim.

Despite the above, other legally-binding constraints come into effect when decommissioning is required either within or close to an MPA. Under European Drivers, a network of MPAs in European 
seas have been designated e.g. Special Protection Areas (SPAs) under the Wild Birds Directive (79/409/EEC) and Special Areas of Conservation (SACs) under the Habitats Directive (92/43/EEC). National legislation also allows the designation of additional offshore MPAs; for example, the UK Marine and Coastal Access Act 2009 allows further designations of Marine Conservation Zones (MCZs) in UK offshore waters. All these MPAs protect important habitats and features from the damaging effects of human activity, but have been designated with many offshore industries already operating within their boundaries. The UK overarching Driver for a vision of a 'clean, healthy, safe, productive, biologically diverse marine and coastal environment' (Defra, 2002; HM Government, 2011) requires the protection of the marine environment, and therefore any decommissioning activities should demonstrate no likely significant effect on the designated conservation features of the site during the process.

\section{Activities}

There has been some confusion in the past between Drivers and Pressures (when applying the DPSIR framework; see for example Patricio et al., 2016; Elliott et al., 2017) and therefore this study follows the DAPSI(W)R(M) framework in making the distinction between Drivers, Activities and Pressures. Decommissioning methods for oil and gas structures depend on a combination of the infrastructure to be removed (e.g. platform wells, subsea wells, platform topsides, platform topsides, pipelines and umbilicals, drill cuttings), the objective of the decommissioning (e.g. plug and abandon, full removal, partial removal, leave in situ) and the methods employed to decommission the specific infrastructure type (e.g. use of a jack-up rig, piecemeal removal, reverse installation). This produced 21 decommissioning combinations of Infrastructure-Objective-Method (Table 3). It is of note that when a Heavy Lifting Vessel is applied, there are two methods of anchoring (embedment and suction) and therefore three of the methods have been sub-divided as they lead to different Pressures. This table was generated specifically for this study, and has been verified by representatives from the regulator, industry, SNCBs and oil and gas consultants. Based on expert judgement, 24 potential Activities have been identified (Table 4) which are required to deliver the 21 methods listed in (Table 3). It is emphasised that whichever option is selected, decommissioning must be carried out in a sustainable manner to protect the marine environment.

\section{Insert Table 3 here}

\section{Insert Table 4 here}

\section{Pressures}

Each Activity (Table 4) is likely to cause one or more Pressures on the marine environment, resulting in the mechanisms of environmental change (JNCC, 2018). Given the focus here on decommissioning of oil and gas structures within MPAs, the sensitivity of the marine features of interest will dictate the potential effect of such Pressures. Pressure types were derived from the list created and agreed by the OSPAR Intercessional Correspondence Group on Cumulative Effects (ICG-C), which identified a total of 31 different Pressures. These were grouped into six separate Pressure themes with a detailed description for each Pressure provided (OSPAR, 2011). The full list of marine Pressures has been refined to include only those 22 Pressures deemed of relevance to oil and gas decommissioning (Table 5).

\section{Insert Table 5 here}




\section{State changes}

State changes reflect the potential effect of Pressures on the natural system, which comprises both physico-chemical (abiotic) and ecological (biotic) capital (Atkins et al., 2014). A recent review of the scientific evidence base for decommissioning impacts on MPAs (Mazik et al., 2018) primarily focusses on the evidence base relating to the benthos (e.g. Coates et al., 2014; Coolen et al., 2015), fish (e.g. Claisse et al., 2015), and marine mammals (e.g. Gomez et al., 2016). As long as the natural system has an appropriate structure and is functioning properly, it has the potential to provide a set of ecosystem services which can then lead to goods and benefits for society (Atkins et al., 2014; Turner et al., 2015). Thus, any impact on the physico-chemical or ecological structure and functioning could affect the delivery of ecosystem services. Turner et al. (2015) identify the key ecosystem services provided by the marine environment (Figure 2). This categorisation distinguishes between the underlying components and processes of the marine environment, the intermediate and final ecosystem services and the goods and benefits which can be obtained by society. Importantly, the potential effect of any Pressure on ecosystem service delivery may be positive or negative and therefore the direction of any State change needs to be identified. Given the focus of the framework on MPAs, the matrices which identify the relative importance of UK marine features (habitats, species and seabirds) in providing the key ecosystem services (after Turner et al., 2015) can be used to identify the key ecosystem services which may be affected by the Pressures (Potts et al., 2014; Saunders et al., 2015; Burdon et al., 2017). Once key ecosystem services have been identified, a qualitative assessment, based on the literature and expert opinion can be employed to assess the magnitude direction of State change (positive or negative) for each ecosystem service. The present framework builds on previously undertaken qualitative assessments in relation to seabed restoration (Cooper et al., 2013) and the decommissioning of offshore wind farms (Smyth et al., 2015) following guidance from the UK Department of Environment, Food and Rural Affairs (Defra, 2007).

\section{Insert Figure 2 here}

\section{Impacts (on Welfare)}

In turn, any State changes in the natural environment, including the ecosystem services which are provided, have the potential to Impact the Welfare of society (either positively or negatively and including well-being). With the addition of complementary capital (e.g. assets such as time, energy, skills and finance comprising built, human or social capital), a range of goods and benefits can be obtained by society from the marine environment (Figure 2). The matrix approach (after Potts et al., 2014; Saunders et al., 2015; Burdon et al., 2017) can again be applied to identify the key goods and benefits which may be at risk as a result of decommissioning operations. The decommissioning Activities, and their associated Pressures and State changes can therefore also have positive or negative impacts on the delivery of these goods and benefits and thus trade-offs must be assessed when comparing the Impacts on Welfare of different decommissioning options (e.g. Smyth et al., 2015).

\section{Responses (as Measures)}

Finally, management Responses, termed Measures in the European Directives mentioned above, are then needed to address the potential Pressures, State changes and Impacts (on Welfare). With respect 
to decommissioning of oil and gas infrastructure in MPAs, management Responses may include: assessing the potential impacts of decommissioning Activities on the Conservation Objectives; reevaluating selected decommissioning Activities to reduce the potential impact of the Activities; applying mitigation and/or compensation Measures to reduce negative State changes and Impacts (on Welfare), and introducing management Measures to further enhance gains in goods and benefits. Such Responses provide feedback loops within the system as outlined above.

Thus far, the DAPSI(W)R(M) components have been described independently from each other, but Atkins et al. (2011) and Elliott et al. (2017) emphasised that multiple Drivers can lead to multiple Activities, which in turn can lead to multiple Pressures and so forth and the same Pressures can emanate from different Activities. A brief illustration of this for decommissioning oil and gas infrastructures (Figure 3 ) indicates the complexity of decommissioning activities within MPAs, and thus the challenges that are faced by the regulator, industry and SNCBs, in ensuring that the decommissioning operations have a minimal impact on the condition of MPAs. This complexity is further demonstrated in summarising the relationships between decommissioning methods and their constituent Activities (Table 6) and relationships between the Activities and Pressures (Table 7).

\section{Insert Figure 3 here}

\section{Insert Table 6 here}

\section{Insert Table 7 here}

This approach demonstrates the need for, and the value of, applying the DAPSI(W)R(M) framework to illustrate and interrogate the complexity of decommissioning oil and gas infrastructures within MPAs. However, to make such a framework operational, a tool is required which enables end-users to untangle this complexity, focussing on the specific decommissioning options required within any given MPA, and identifying the features, ecosystem services and/or goods and benefits which may potentially be affected (positively or negatively) from such decommissioning operations.

\section{SPIDA Database Tool}

As indicated above, none of the frameworks and tools currently available address all of the eight questions of interest (Figure 1, Table 8); hence, there is the need to develop a database tool to link a number of existing tools. Applying the operational decision support framework has produced a proofof-concept evidence-based tool, which allows the above relationships and complexity to be mapped and interrogated. This application, SPIDA (Screening Potential Impacts of Decommissioning Activities), was developed in Microsoft Access as an interactive tool that can be used to screen for the potential impacts of decommissioning activities.

\section{Insert Table 8 here}

SPIDA has a modular structure, which draws on several underlying data tables. These tables outline: the potential decommissioning Methods (Table 3); the relationship between these Methods and the discrete Activities through which they are delivered (Table 6); the Pressures that are likely to be generated by the constituent Activities (Table 7), and the sensitivity of selected marine conservation features to these Pressures (based on the Marine Evidence based Sensitivity Assessment (MarESA); 
MarLIN, 2018, or taken from Tillin et al., 2010). The adopted structure for the SPIDA development permits the tool to be updated relatively easily when new or revised data become available. Furthermore, an intuitive and user-friendly interface allows the user to identify the infrastructure type and decommissioning objective, and to select the proposed decommissioning method (Figure 4).

\section{Insert Figure 4 here}

Algorithms are not currently available to describe the likely spatial extent, duration and frequency of decommissioning Activities (or resultant Pressures) (i.e. their spatio-temporal footprints). It is nevertheless recognised that such information is important for assessing the likely significance of the environmental effects of Activities, and in considering whether Pressures are likely to exceed benchmark levels. To address this requirement, SPIDA first identifies the range of Activities that would be associated with the proposed decommissioning scenario, and then provides a utility to capture expert judgement regarding the likely spatio-temporal footprint associated with each Activity (see Table 9). The use of expert judgement to support decision-making has always played a large role in science and engineering (Barnard \& Boyes, 2013) and in managing complex marine areas (Elliott et al., 2018). Expert judgement is routinely recognised as representing a certain type of data (Goossens et al., 2008); and it may be argued that the use of expert judgement in relation to technical problems is not only often unavoidable, but is also desirable (Keeny \& von Winterfeldt, 1989). This novel approach embedded within SPIDA enables case-specific details to be included in the resultant assessments.

\section{Insert Table 9 here}

The software user is able to select from a list of 16 features of interest (including habitats and species), representing the range of designated features within those UK MPAs that currently contain elements of oil and gas infrastructure (Table 10), and to identify a minimum level of feature sensitivity to be considered in reporting (effectively High, Medium, Low and combinations thereof). The software cross-references the known sensitivity of the selected feature against this selected cut-off value and, where a feature's sensitivity to any given Pressure is below the cut-off, it is assumed that the feature will not be adversely affected by that Pressure. Conversely, where a feature's sensitivity to a Pressure is above the cut-off there is an assumption that the feature may be adversely affected, and both the Pressure, and the Activity that potentially gives rise to it, are flagged by the software and are reported in the sensitivity outputs (Figure 5). In a similar way, the SPIDA tool is also able to indicate which intermediate ecosystem services and goods and benefits may be affected, based on the importance of the feature in delivering particular services, goods and benefits (after Potts et al., 2014; Saunders et al., 2015; Burdon et al., 2017).

\section{Insert Table 10 here \\ Insert Figure 5 here}

The strength of the SPIDA tool is that it's outputs are presented in a clear, standardised format, which enables the potential environmental impact of multiple decommissioning methods to be compared. The first output generated by the SPIDA tool is an assessment of the potential environmental impacts on designated features within the site (see Figure 5, Q6 in Figure 1). In addition, SPIDA also generates a summary of the key intermediate ecosystem services ( $Q 7$ in Figure 1 ) and societal goods and benefits (Q8 in Figure 1) which may be affected based on the established relationships between the features 
and the relative provision of ecosystem services and goods and benefits (after Saunders et al., 2015; Burdon et al., 2017). These latter outputs identify the focus for further assessments, based on ecosystem service indicators (Atkins et al., 2015; Hattam et al., 2015) which could assess the magnitude and direction of the State change (i.e. intermediate ecosystem services) and Impact on Welfare (i.e. the goods and benefits) of a given decommissioning scenario.

\section{Discussion}

The transparent decision support framework developed and applied here to produce a database tool (SPIDA) allows for the screening of potential impacts of decommissioning Activities. The study has focused on identifying the environmental impacts of oil and gas decommissioning Activities within UK MPAs but the flexible modular structure of SPIDA, and the transparency of the underlying decision support framework could easily be applied to decommissioning within other sectors, such as those relating to offshore wind developments (Smyth et al., 2015), or even to other Activities such as the impacts of fisheries or aggregate extraction on MPAs. Similarly, the focus on UK MPAs relates to those features currently protected by MPAs, and which have oil and gas infrastructure within them, but again, the modular structure of SPIDA has the in-built flexibility to broaden the number and type of features, thus having global relevance to MPAs as well as the wider non-protected marine environment. The transparency, transportability and flexibility of both the decision support framework and the underlying resources also allows a range of data types to be incorporated (e.g. quantitative, qualitative, expert opinion).

The SPIDA tool does not replace the requirement for an Environmental Impact Assessment (EIA), comparative assessment or derogation case applications undertaken by industry, but complements these regulatory procedures to improve the decision-making process. EIA will continue to be required in the planning and consenting process for any plan or project, but increasingly, approaches based around a series of linked matrices are being used by developers to support their decision-making process. By increasing the understanding of the links between the Pressures associated with particular decommissioning Activities and the sensitivities to those Pressures of marine habitats and species, the tool enhances industry's decision-making capability with respect to decommissioning options within and close to MPAs. Hence, the tool provides support in meeting the needs of industry against an increasing decommissioning workload, whilst increasing the importance of conservation issues.

The outputs from the SPIDA tool support regulatory managers in making legislative and policy decisions by providing further understanding of the decommissioning options and their environmental impact within MPAs. The SPIDA tool aims to make such decisions more rigorous, defendable and transparent for the industry developers, the regulatory bodies and the nature conservation bodies, and indeed for any NGO wishing to challenge a decision. To help satisfy this range of aims, both the decision support framework and the SPIDA tool were produced and steered in cooperation with representatives from the regulator, industry, SNCBs, consultancies and academia. The development of the framework and SPIDA tool have been constantly reviewed and refined following feedback and via road-testing at two stakeholder engagement workshops. For example, initial feedback from stakeholders identified the requirement for case-specific information to feed into the process, to ensure that decisions were not based upon a purely generic framework. This has been achieved within SPIDA, with the inclusion of an additional assessment stage where spatial extent, duration and 
frequency of an Activity are incorporated. Such stakeholder engagement is essential to ensure the tool and approach are consistent with stakeholder demands and are fit-for-purpose.

The scope of SPIDA, and the underlying decision support framework, have focused on environmental issues, specifically with respect to impacts of decommissioning operations on MPAs. However, it is recognized here that the environmental aspects are only one facet of decommissioning. The BEIS guidance for comparative assessments requires that the chosen approach must demonstrate understanding of safety, environmental, societal, technological and economic impacts (BEIS, 2018), not least because the taxpayer carries the major burden of decommissioning costs. In addition to the local nature conservation considerations, there are additional implications regarding, for example, energy use (and therefore greenhouse gas production) during infrastructure removal, and hence wider-scale repercussions if preventing global environmental change is a priority. As such, decommissioning management requires a holistic approach. It has been suggested that successful marine management should focus on a set of 10-tenets which incorporate all multidisciplinary aspects (Elliott, 2013; Barnard \& Elliott, 2015). The application of the 10-tenets to oil and gas decommissioning (Table 11) shows that in particular the technological, economic and legal aspects are paramount in dictating both the course of action and the business case for oil and gas decommissioning. It is of note that 9 out of the 10 tenets are social in nature, thus emphasising the importance of integrating natural and social science research (Burdon, 2016; Burdon et al., 2018). Furthermore, such a holistic approach has wider application outside of the oil and gas industry; for example, the concepts presented also hold true for offshore windfarm decommissioning (Smyth et al., 2015).

\section{Insert Table 11 here}

In addition to the requirements of the Regional Seas Conventions discussed earlier, the decommissioning of oil and gas installations has implications for meeting the legally binding requirements of European Directives. The effects of decommissioning on Good Environmental Status (GES) under the Marine Strategy Framework Directive (MSFD) and uses and users under the Maritime Spatial Planning Directive (MSPD) need to be considered (see also Boyes et al., 2016; Elliott et al., 2018). Hence, the influence of the many Pressures created by decommissioning Activities needs to be determined for their positive or negative effect on the 11 MSFD descriptors (Table 12) which in turn will influence achieving GES. GES therefore requires the descriptors to be defined quantitatively (using indicators) and the management of any environmental Pressure relies on monitoring to detect a given amount of change, such as a deviation from GES. True monitoring requires an unacceptable level of change to be defined either by an operator or a regulator, i.e. as a change against an accepted baseline, threshold or target (Borja et al., 2017), and this may be set as a condition in a permit or licence. In the case of MPA management, such unacceptable levels of change can only be defined against stipulated conservation objectives and these should be quantitative.

\section{Insert Table 12 here}

Marine plans, developed to meet the requirements of the MSPD, inform when and where human activities take place at sea to support sustainable development and growth in the maritime sector (Elliott et al., 2018). As decommissioning activities increase, marine planning must be an adaptive process, hence the need for a flexible and transparent approach as described here. Removing the platforms and associated infrastructure leads to a potential change in maritime use with spatial 
competition effectively removed; for example, fishing activities could re-engage with the area formerly restricted by the safety exclusion zones around infrastructure.

\section{Challenges and Future Work}

This paper and the tool produced have identified the complexity of decommissioning within the marine environment and the additional challenges associated with undertaking such activities within MPAs (Box 1). In providing a rigorous, transparent and defendable decision support framework, the tool allows industry and regulators to make evidence-based judgements regarding the need to remove, or to consider derogations to leave in place, the obsolete infrastructure. This requires not only the impediments to action to be considered, but also the implications of the actions on the other maritime uses and users.

\section{Box 1: Marine environmental challenges from oil and gas decommissioning}

- the loss and gain of habitats and surfaces;

- the loss and gain of ecosystem services and societal goods and benefits;

- the value of removing structures with and without damage;

- the whole system energy and economic budgets;

- the whole cycle environmental footprints at near and far scales;

- the determination of whether an area will regain a pre-construction equilibrium if a structure is removed;

- how to ensure the protection of other maritime uses and users;

- the relevant baseline/reference condition (with or without structures);

- the harmonised implementation of Good Ecological Status (WFD), Good Environmental Status (MSFD) and Favourable Conservation Status (HD), and

- determining the bottlenecks, showstoppers and train-wrecks (Newton \& Elliott, 2016).

This conceptual paper has attempted to address a number of these challenges although there are opportunities to further develop the concept and to undertake rigorous testing of the tool. Future developments will include: applying the framework to a range of industry-led scenarios to demonstrate its real world applicability; improving knowledge of the key elements of the framework e.g. the Activities-Pressures relationships, and developing a combined scoring system ('SpatioTemporal Footprint Index') for assessing the spatial extent, duration and frequency of each Activity. It also relies on increasing our understanding and quantification of the ecosystem service components (based on ecosystem service indicators) to enable an assessment of the trade-offs between services and societal goods and benefits under different scenarios.

\section{Acknowledgements}

The authors acknowledge funding under the NERC Oil \& Gas Innovation Programme (Ref: NE/P016553/1) for the DECOM-MPA project. The authors also wish to thank all the project partners (BEIS, Shell UK Ltd., JNCC, Natural England, University of Hull, Heriot Watt University, Hartley Anderson Ltd.) and the wide range of stakeholders who have engaged with and provided valuable feedback on both the framework presented here and the DECOM-MPA project. 


\section{References}

Atkins, J.P., Burdon, D. \& Elliott, M., 2015. Chapter 5. Identification of a practicable set of indicators for coastal and marine ecosystem services. In: Turner, R.K. \& Schaafsma, M. (Eds.) Coastal zones ecosystem services: from science to values and decision making. Studies in Ecological Economics, Volume 9, Springer, Switzerland.

Atkins, J.P., Burdon, D., Elliott, M. \& Gregory, A.J., 2011. Management of the marine environment: integrating ecosystem services and societal benefits with the DPSIR framework in a systems approach. Marine Pollution Bulletin, 62, pp. 215-226.

Atkins, J.P., Burdon, D., Elliott, M., Schaafsma, M. \& Turner, R.K., 2014. Coastal and marine ecosystem services. Environmental Scientist, 23(4), pp. 26-30.

Barnard, S. \& Boyes, S.J., 2013. Review of Case Studies and Recommendations for the Inclusion of Expert Judgement in Marine Biodiversity Status Assessments. A report for the Joint Nature Conservation Committee, JNCC Report No.490 by the Institute of Estuarine and Coastal Studies, University of Hull.

Barnard, S. \& Elliott, M., 2015. The 10-tenets of adaptive management and sustainability - applying an holistic framework for understanding and managing the socio-ecological system. Environmental Science \& Policy, 51, pp. 181-191.

BEIS, 2018. Decommissioning of offshore oil and gas installations and pipelines: Guidance notes. Department for Business, Energy \& Industrial Strategy, Aberdeen, May 2018. 124 pp.

Bernstein, B.B., 2015. Decision framework for platform decommissioning in California. Integrated Environmental Assessment and Management, 11, pp. 542-553.

Borja, A., Elliott, M., Uyarra, M.C., Carstensen, J. \& Mea, M., 2017. Editorial: Bridging the Gap Between Policy and Science in Assessing the Health Status of Marine Ecosystems. Frontiers in Marine Science 4:32 doi: 10.3389/fmars.2017.00032.

Boyes, S.J., Elliott, M., Murillas-Maza, A., Papadopoulou, N. \& Uyarra, M.C., 2016. Is existing legislation fit-for-purpose to achieve Good Environmental Status in European seas? Marine Pollution Bulletin, 111, pp. 18-32.

Burdon, D., 2016. An interdisciplinary approach to marine management: Bridging the divide between natural and social sciences research. PhD by published work, University of Hull, UK.

Burdon, D., Boyes, S.J., Elliott, M., Smyth, K., Atkins, J.P., Barnes, R.A. \& Wurzel, R.K., 2018. Integrating natural and social marine science to manage sustainably vectors of change: Dogger Bank transnational case study. Estuarine, Coastal and Shelf Science, 201, pp. 234-247.

Burdon, D., Potts, T., Barbone, C. \& Mander, L., 2017. The matrix revisited: A bird's-eye view of marine ecosystem service provision. Marine Policy, 77, pp. 78-89.

CBD, 2000. Convention on Biological Diversity. http://69.90.183.227/doc/legal/cbd-un-en.pdf. 
Chandler, J., White, D., Techera, E.J., Gourvenec, S. \& Draper, S. 2017. Engineering and legal considerations for decommissioning of offshore oil and gas infrastructure in Australia. Ocean Engineering, 131, pp. 338-347.

Claisse, J.T., Pondella, D.J., Love, M., Zahn, L.A., Williams, C.M. \& Bull, A.S., 2015. Impacts from partial removal of decommissioned oil and gas platforms on fish biomass and production on the remaining platform structure and surrounding shell mounds. PLOS ONE 10(9): e0135812. doi:10.1371/journal. pone. 0135812

Coates, D.A., Deschutter, Y., Vincx, M. \& Vanaverbecke, J., 2014. Enrichment and shifts in macrobenthic assemblages in an offshore wind farm area in the Belgian part of the North Sea. Mar. Env. Res., 95, pp. 1-12.

Coolen, J.W.P., Lengkeek, W., Lewis, G., Bos, O.G., van Walraven, L. \& van Dongen, U., 2015. First record of Caryophillia smithii in the central southern North Sea: artificial reefs affect range extensions of sessile benthic species. Marine Biodiversity Records, 8, pp. 1-4.

Cooper, K., Burdon, D., Atkins, J.P., Weiss, L., Somerfield, P., Elliott, M., Turner, K., Ware, S. \& Vivian, C., 2013. Can the benefits of physical seabed restoration justify the costs? An assessment of a disused aggregate extraction site off the Thames Estuary, UK. Marine Pollution Bulletin, 75, pp.33-45.

Defra, 2002. Safeguarding our Seas report.

www.defra.gov.uk/environment/marine/documents/marine_stewardship.pdf

Defra, 2007. An introductory guide to valuing ecosystem services. Defra, London, $65 \mathrm{pp}$.

Elliott, M., 2011. Marine science and management means tackling exogenic unmanaged pressures and endogenic managed pressures - a numbered guide. Marine Pollution Bulletin, 62, pp. 651-655.

Elliott, M., 2013. The 10-tenets for integrated, successful and sustainable marine management. Marine Pollution Bulletin, 74(1), pp. 1-5.

Elliott, M., Boyes, S., Barnard, S. \& Borja, A. (2018) Using best expert judgement to harmonise marine environmental status assessment and marine spatial planning. Marine Pollution Bulletin, 133, pp. 367377.

Elliott, M., Burdon, D., Atkins, J.P., Borja, A., de Jonge, V.N. \& Turner, R.K., 2017. "And DPSIR begat DAPSI(W)R(M)!" - a unifying framework for marine environmental management. Marine Pollution Bulletin, 118, pp. 27-40.

Fletcher, S., Saunders, J., Herbert, R., Roberts, C. \& Dawson, K., 2012. Description of the ecosystem services provided by broad-scale habitats and features of conservation importance that are likely to be protected by Marine Protected Areas in the Marine Conservation Zone Project area. Natural England Commissioned Reports, Number 088.

Gomez, C., Lawson, J.W., Wright, A.J., Buren, A., Tollit, D. \& Lesage, V., 2016. A systematic review on the behavioural responses of wild marine mammals to noise: the disparity between science and policy. Can. J. Zool., 94, pp. 801-819. 
Goossens, L.H.J., Cooke, R.M., Hale, A.R. \& Rodic'-Wiersma, Lj., 2008. Fifteen years of expert judgement at TUDelft. Safety Science, 46, pp. 234-44.

Hattam, C., Atkins, J.P., Beaumont, N., Borger, T., Böhnke-Henrichs, A., Burdon, D., De Groot, R., Hoefnagel, E., Nunes, P., Piwowarczyk, J., Sergio, S. \& Austen, M., 2015. Marine ecosystem services: linking indicators to their classification. Ecological Indicators, 49, pp. 61-75.

HELCOM, 1993. HELCOM Recommendation 14/9: Removal of Abandoned and Disused Offshore Units. Adopted 3 February 1993.

Henrion, M., Bernstein, B. \& Swamy, S., 2015. A multi-attribute decision analysis for decommissioning offshore oil and gas platforms. Integrated Environmental Assessment and Management, 11, pp. 594609.

HM Government, 2011. UK Marine Policy Statement. HM Government, Northern Ireland Executive, Scottish Government, Welsh Assembly Government. March 2011

JNCC, 2018. Marine activities and pressures evidence. Accessed 10/01/2018. http://jncc.defra.gov.uk/page-7136

Kaiser, M.J. \& Pulsipher, A.G., 2005. Rigs-to-reef programs in the Gulf of Mexico. Ocean Dev. Int. Law 36, pp. 119-134.

Keeney, R.L \& Von Winterfeldt, D., 1989. On the uses of expert judgement on complex technical problems. IEEE Transactions on Engineering Management, 36(2), pp. 83-6.

Marine Scotland, 2018. FEAST - Feature Activity Sensitivity Tool. Accessed 10/01/2018 http://www.marine.scotland.gov.uk/feast/

MarLIN, 2018. Marine Evidence based Sensitivity Assessment (MarESA). Accessed 09/02/2018 https://www.marlin.ac.uk/species/sensitivity_rationale\#top

Mazik, K., Boyes, S.J., Fernandes, T. \& Ricottone, V., 2018. Ecological implications of offshore decommissioning: Considerations for marine protected areas. Unpublished report for the DECOMMPA project. Institute of Estuarine \& Coastal Studies, University of Hull, Hull, UK (Ref: YBB343).

Net Gain, 2011. Net Gain Final Recommendations Submission to Natural England \& JNCC, 31 August 2011 [available from online archive at: http://www.nationalarchives.gov.uk/webarchive/]

Newton, A. \& Elliott, M., 2016. A typology of stakeholders and guidelines for engagement in transdisciplinary, participatory processes. Front. Mar. Sci. 3:230. doi: 10.3389/fmars.2016.00230

Oil and Gas UK, 2017. Decommissioning Insight 2017. Accessed 14/02/2018

https://oilandgasuk.co.uk/wp-content/uploads/2017/11/Decommissioning-Report-2017-27-Novfinal.pdf

OSPAR, 1998. OSPAR Decision 98/3 on the Disposal of Disused Offshore Installations. 
OSPAR, 2011. Pressure list and descriptions. Paper to ICG-COBAM (1) 11/8/1 Add.1-E (amended version 25th March 2011) presented by ICG-Cumulative Effects.

Patrício, J., Elliott, M., Mazik, K., Papadopoulou, K.-N. \& Smith, C.J., 2016. DPSIR-Two decades of trying to develop a unifying framework for marine environmental management? Front. Mar. Sci., 3, 177. doi: $10.3389 /$ fmars.2016.00177.

Potts, T., Burdon, D., Jackson, E., Atkins, J.P., Saunders, J., Hastings, E. \& Langmead, O., 2014. Do marine protected areas deliver flows of ecosystem services to support human welfare? Marine Policy, 44, pp. 139-148.

Reggio, V.C.J., 1987. Rigs-to-reefs. Fisheries, 12, pp. 2-6.

Rouse, S., Kafas, A., Catarino, R. \& Peter, H., 2017. Commercial fisheries interactions with oil and gas pipelines in the North Sea: considerations for decommissioning. ICES Journal of Marine Science, doi:10.1093/icesjms/fsx121.

Saunders, J., Potts, T., Jackson, E., Burdon, D., Atkins, J.P., Hastings, E. \& Langmead, O., 2015. Chapter 9. Linking ecosystem services of marine protected areas to benefits in human wellbeing? In: Turner, R.K. \& Schaafsma, M. (Eds.) Coastal zones ecosystem services: from science to values and decision making. Studies in Ecological Economics Volume 9, Springer, Switzerland.

Schroeder, D.M. \& Love, M.S., 2004. Ecological and political issues surrounding decommissioning of offshore oil facilities in the Southern California Bight. Ocean \& Coastal Management, 47, pp. 21-48.

Smyth, K., Christie, N., Burdon, D., Atkins, J.P., Barnes, R.A. \& Elliott, M., 2015. Renewables-to-Reefs? - Decommissioning options for the offshore wind power industry. Marine Pollution Bulletin, 90, pp. 247-258.

Tillin, H.M., Hull, S.C. \& Tyler-Walters, H. 2010. Development of a Sensitivity Matrix (pressuresMCZ/MPA features). Report to the Department of Environment, Food and Rural Affairs from ABPMer, Southampton and the Marine Life Information Network (MarLIN) Plymouth: Marine Biological Association of the UK. Defra Contract No. MB0102, Task 3A, Report No. 22.

Turner, R.K., Schaafsma, M., Mee, L., Elliott, M., Burdon, D., Atkins, J.P. \& Jickells, T., 2015. Chapter 2. Conceptual framework. In: Turner, R.K. \& Schaafsma, M. (Eds.) Coastal zones ecosystem services: from science to values and decision making. Studies in Ecological Economics, Volume 9, Springer, Switzerland. 
Table 1: Elements of the DAPSI(W)R(M) framework of relevance to decommissioning.

\begin{tabular}{ll}
\hline Element & Relevance to Decommissioning \\
\hline Drivers & $\begin{array}{l}\text { Legal and societal demand for a clean, safe, productive, diverse and healthy } \\
\text { environment. }\end{array}$ \\
\hline Activities & $\begin{array}{l}\text { Appropriate decommissioning options and their associated activities e.g. removal of } \\
\text { rigs, burying or removal of pipelines, removal of rock protection. }\end{array}$ \\
\hline Pressures & $\begin{array}{l}\text { Wide-scale pressure list: above-water noise, abrasion, siltation, collision risk, } \\
\text { contamination by chemicals, litter, light, etc. }\end{array}$ \\
\hline State changes & $\begin{array}{l}\text { Potential biological loss, gain or damage to the hydrodynamics, ecology, ecosystem } \\
\text { services, such as smothering of the benthos, resuspension of sediments and re- } \\
\text { liberation of contaminants. }\end{array}$ \\
\hline $\begin{array}{l}\text { Impacts (on } \\
\text { Welfare) }\end{array}$ & $\begin{array}{l}\text { Potential loss or gain of societal goods and benefits; commercial, recreational and } \\
\text { cultural aspects, such as increase or decrease in fisheries, changes to recreation near } \\
\text { developments. }\end{array}$ \\
\hline $\begin{array}{l}\text { Responses (as } \\
\text { Measures) }\end{array}$ & $\begin{array}{l}\text { Management measures such as legal controls, technological advances or economic } \\
\text { instruments to further enhance the provision of ecosystem services; mitigation } \\
\text { and/or compensation measures to minimise effects. }\end{array}$ \\
\hline
\end{tabular}


Table 2: Scope of the Decision Support Framework.

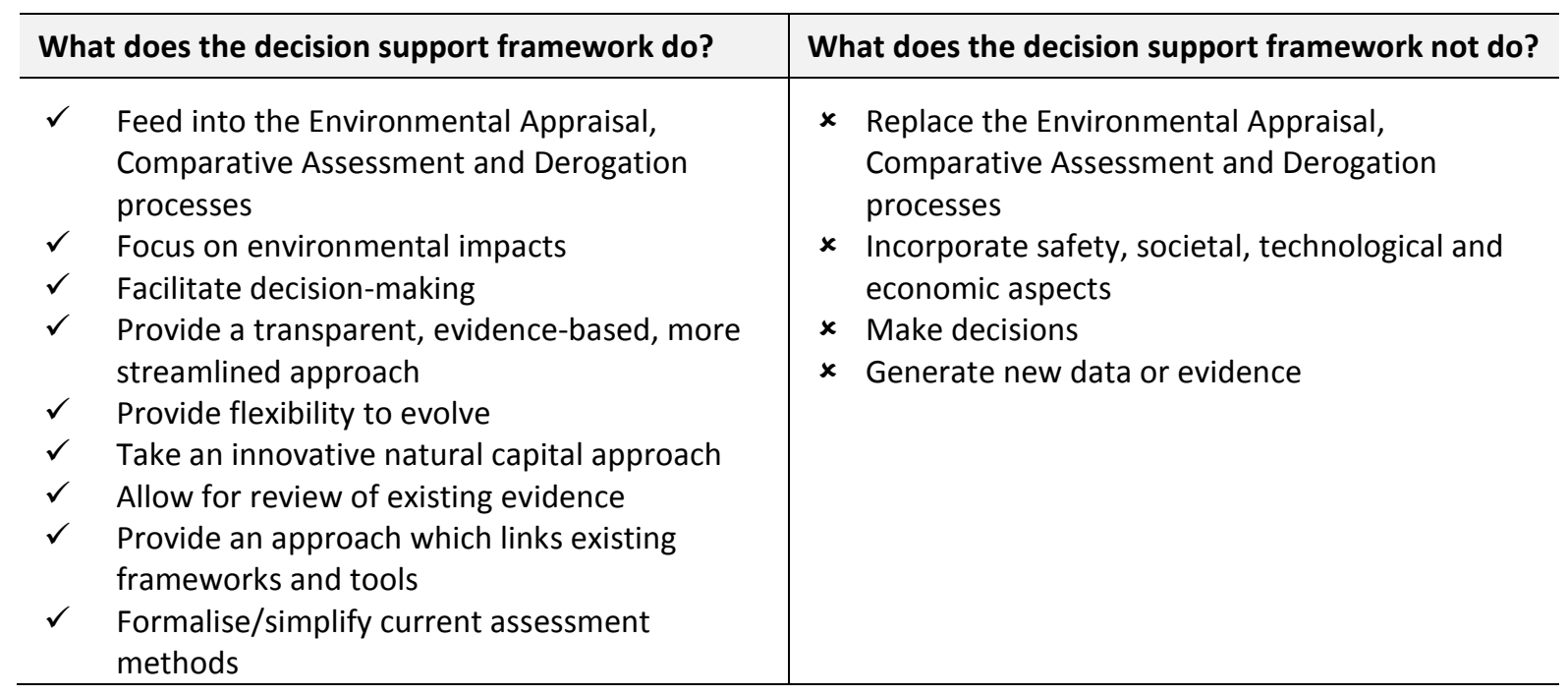


Table 3: Summary of potential decommissioning approaches for the oil and gas industry.

\begin{tabular}{|c|c|c|c|}
\hline & Infrastructure & Objective & Method \\
\hline 1 & Platform wells & Plug and abandon & Existing integrated facilities \\
\hline 2 & Platform wells & Plug and abandon & "Rigless" modular units \\
\hline 3 & Platform wells & Plug and abandon & Jack-up rig \\
\hline 4 & Subsea wells & Plug and abandon & Jack-up rig \\
\hline 5 & Subsea wells & Plug and abandon & Light well-intervention vessel \\
\hline 6 & Platform topsides & Full removal & $\begin{array}{l}\text { Piecemeal removal involving demolition in situ, and } \\
\text { multiple smaller ships and possibly crane vessels }\end{array}$ \\
\hline $7(\mathrm{a})$ & Platform topsides & Full removal & $\begin{array}{l}\text { Reverse installation using an anchored Heavy Lifting } \\
\text { Vessel (embedment anchoring) }\end{array}$ \\
\hline $7(b)$ & Platform topsides & Full removal & $\begin{array}{l}\text { Reverse installation using an anchored Heavy Lifting } \\
\text { Vessel (suction anchoring) }\end{array}$ \\
\hline 8 & Platform topsides & Full removal & $\begin{array}{l}\text { Reverse installation using a Dynamically Positioned } \\
\text { Heavy Lifting Vehicle }\end{array}$ \\
\hline 9(a) & Platform topsides & Full removal & $\begin{array}{l}\text { Single lift using an anchored Heavy Lifting Vessel } \\
\text { (embedment anchoring) }\end{array}$ \\
\hline $9(b)$ & Platform topsides & Full removal & $\begin{array}{l}\text { Single lift using an anchored Heavy Lifting Vessel } \\
\text { (suction anchoring) }\end{array}$ \\
\hline 10 & Platform topsides & Full removal & $\begin{array}{l}\text { Single lift using a Dynamically Positioned Heavy Lifting } \\
\text { Vehicle }\end{array}$ \\
\hline 11 & Platform jackets & Full removal & $\begin{array}{l}\text { Multiple lifts using a shear-leg barge or smaller Heavy } \\
\text { Lifting Vehicle }\end{array}$ \\
\hline $12(a)$ & Platform jackets & Full removal & $\begin{array}{l}\text { Single lift using an anchored Heavy Lifting Vessel } \\
\text { (embedment anchoring) }\end{array}$ \\
\hline 12 (b) & Platform jackets & Full removal & $\begin{array}{l}\text { Single lift using an anchored Heavy Lifting Vessel } \\
\text { (suction anchoring) }\end{array}$ \\
\hline$\overline{13}$ & Platform jackets & Full removal & $\begin{array}{l}\text { Single lift using a Dynamically Positioned Heavy Lifting } \\
\text { Vessel }\end{array}$ \\
\hline 14 & Pipelines and umbilicals & Full removal & $\begin{array}{l}\text { "Cut and lift" of pipeline sections: most practical for } \\
\text { large diameter, rigid and concrete coated pipelines, } \\
\text { though applicable to any }\end{array}$ \\
\hline 15 & Pipelines and umbilicals & Full removal & Reverse reel or reverse S-lay \\
\hline$\overline{16}$ & Pipelines and umbilicals & Partial removal & $\begin{array}{l}\text { "Cut and lift" of individual sections [may involve various } \\
\text { degrees of intervention, with removal of pipeline ends } \\
\text { and remediation involving rock placement] }\end{array}$ \\
\hline 17 & Pipelines and umbilicals & Leave in situ & $\begin{array}{l}\text { Usually involves various degrees of intervention, with } \\
\text { removal of pipeline ends and remediation involving rock } \\
\text { placement }\end{array}$ \\
\hline 18 & Pipelines and umbilicals & Leave in situ & Trench and bury \\
\hline 19 & Drill cuttings & Leave in situ & Leave in place \\
\hline 20 & Drill cuttings & Leave in situ & Leave in place but cover with gravel \\
\hline 21 & Drill cuttings & Full removal & $\begin{array}{l}\text { Remove cuttings (pump up to surface rig/vessel), } \\
\text { dewater, and either re-inject into bedrock waste well or } \\
\text { transfer to shore for treatment/landfill }\end{array}$ \\
\hline
\end{tabular}


Table 4: Activities required to satisfy the full combination of Infrastructure-Objective-Methods (JNCC, Peterborough and Aberdeen, pers. comm.).

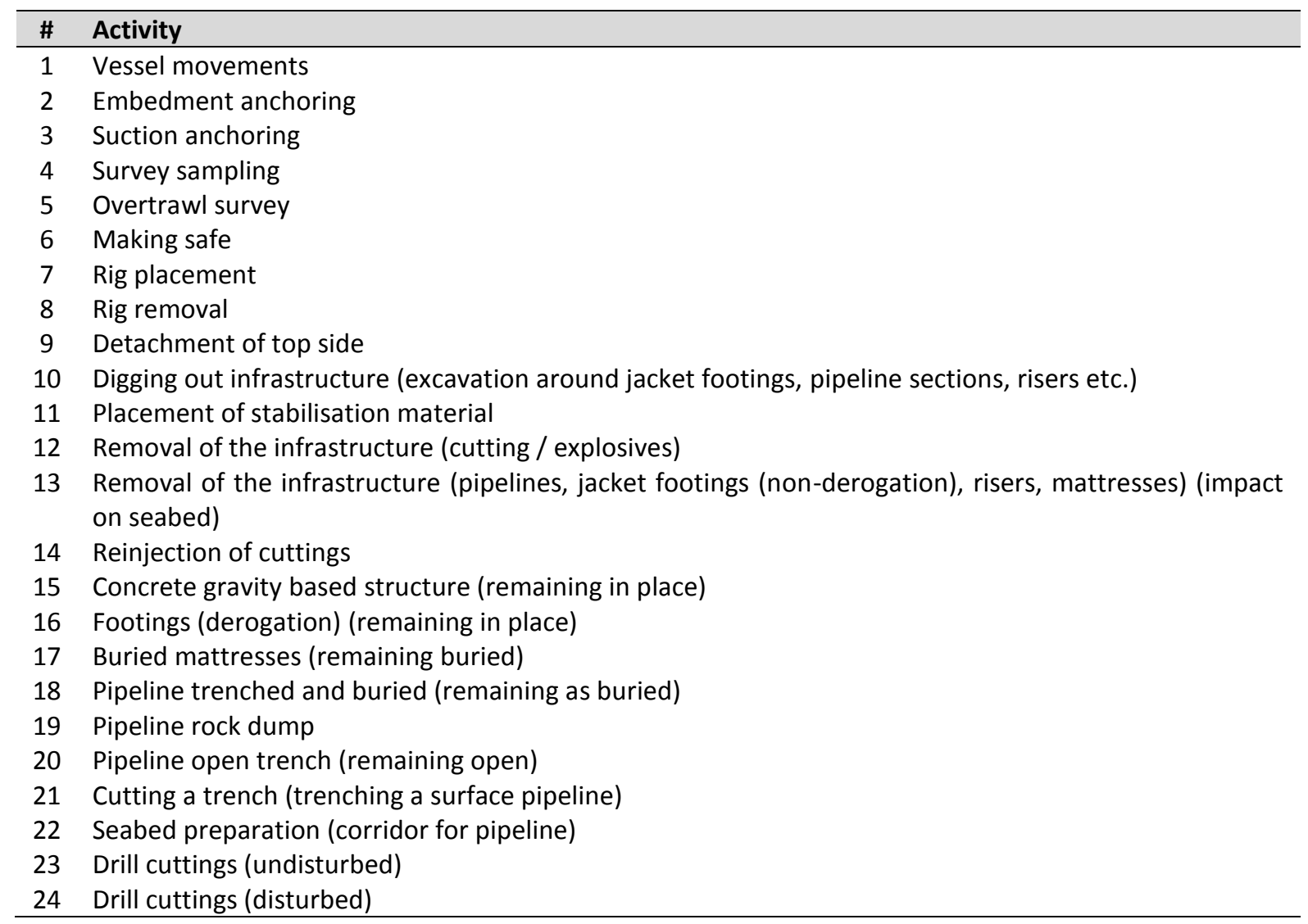


Table 5: Refined list of Pressures identified as currently being of relevance to decommissioning Activities (adapted from OSPAR, 2011).

\section{Pressures}

1. Vibration

2. Above water noise

3. Transition elements \& organo-metal (e.g. TBT) contamination

4. Hydrocarbon \& PAH contamination

5. Synthetic compound contamination

6. Noise changes

7. Introduction of light or shading

8. Death or injury by collision

9. Visual disturbance

10. Introduction or spread of invasive non-indigenous species (INIS)

11. Introduction of microbial pathogens

12. Litter

13. Abrasion/disturbance at the surface of the substratum

14. Penetration and/or disturbance of the substratum below the surface

15. Changes in suspended solids (water clarity)

16. Smothering and siltation rate changes (light)

17. Smothering and siltation rate changes (heavy)

18. Physical change (to another substratum type) - change in sediment type/Folk class

19. Physical change (to another substratum type) - change in substrata

20. Water flow (tidal current) changes - local

21. Barrier to species movement (behaviour, reproduction)

22. Habitat structure changes - removal of substratum (extraction) 
Table 6: Relationships between potential decommissioning Methods and their constituent Activities (indicating where Activities are undertaken as part of a given decommissioning method).

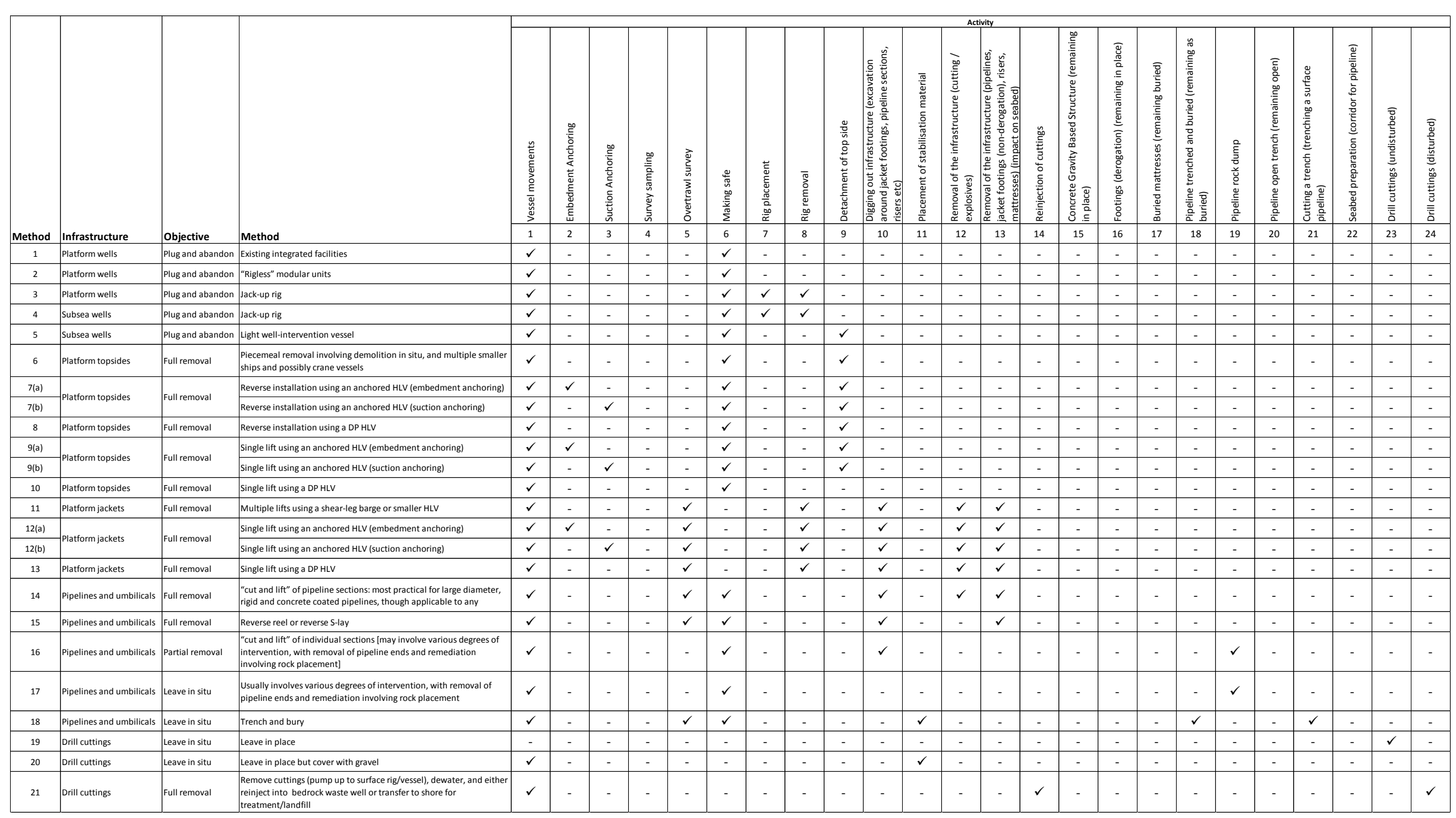

(C) 2019. This manuscript version is made available under the CC-BY-NC-ND 4.0 license http://creativecommons.org/licenses/by-nc-nd/4.0/ 
Table 7: Relationships between constituent Activities and the potential Pressures (indicating where Pressures are likely to be generated as a result of a given Activity).

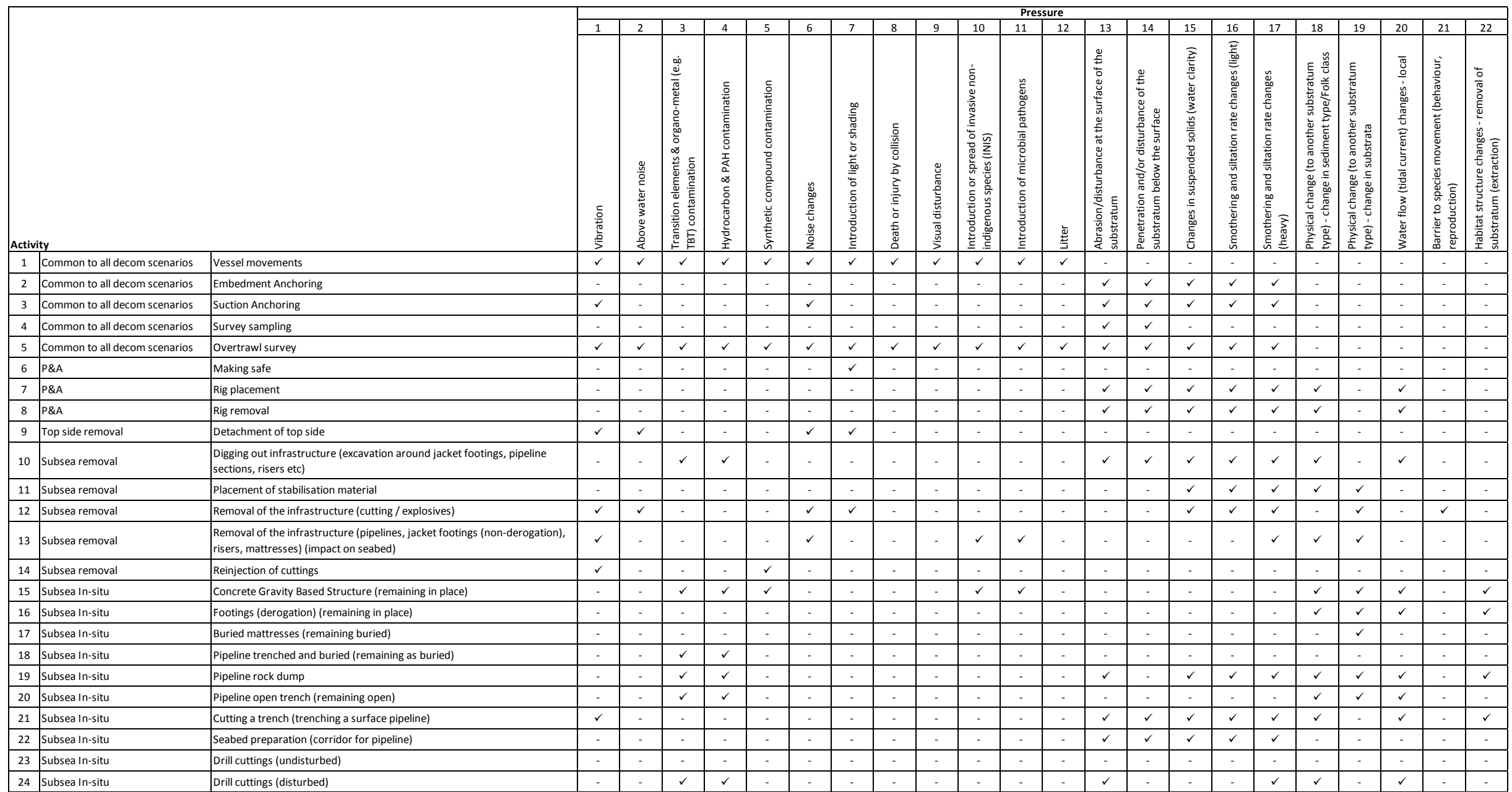


Table 8: Comparison of existing decision support tools / frameworks in addressing the key questions for oil and gas decommissioning (Questions are provided in full in Figure 1).

\begin{tabular}{|c|c|c|c|c|c|c|c|c|c|}
\hline Tool / Framework & Reference & 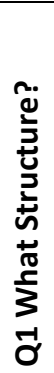 & 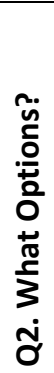 & 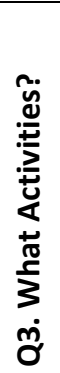 & 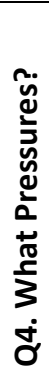 & 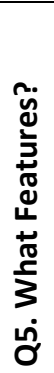 & 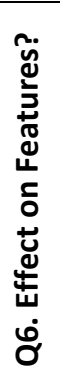 & 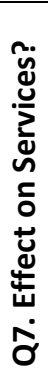 & 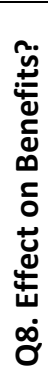 \\
\hline Decision Framework & Bernstein et al. (2015) & & & & & & & & \\
\hline PLATFORM & Henrion et al. (2015) & & & & & & & & \\
\hline PRISM & Net Gain (2011) & & & & & & & & \\
\hline PISA & Net Gain (2011) & & & & & & & & \\
\hline STARFISH & Net Gain (2011) & & & & & & & & \\
\hline FEAST & Marine Scotland (2018) & & & & & & & & \\
\hline ES Matrix Approach & Saunders et al. (2015) & & & & & & & & \\
\hline SPIDA & Current paper & & & & & & & & \\
\hline
\end{tabular}


Table 9: Categories used to record expert judgement on the likely spatio-temporal footprints of decommissioning Activities.

\section{Categories used to record:}

Spatial extent

- Local (0-1m)

- Restricted nearfield (1-10m)

- Nearfield (10-100m)

- Farfield $(100 \mathrm{~m}-1 \mathrm{~km})$

- Widespread (in excess of $1 \mathrm{~km}$ )

\section{Duration}

- Up to 1 day

- Up to 1 week

- Up to 1 month

- Up to 2 weeks

- Up to 2 months

- More than 2 months

\section{Frequency}

- One-off (single occurrence)

- Repeating: minute-by-minute

- Repeating: hourly

- Repeating: daily 
Table 10: Range of features currently considered by SPIDA.

\begin{tabular}{ll}
\hline Interest & Feature \\
\hline Annex I Species & Hydrocoloeus minutus (Little gull) \\
\hline Annex I Species & Sterna albifrons (Little tern) \\
\hline Annex I Species & Sterna hirundo (Common tern) \\
\hline Annex I Habitats & Reefs \\
\hline Annex I Habitats & Sandbanks which are slightly covered with seawater all of the time \\
\hline Annex I Habitats & Submarine structures made by leaking gases \\
\hline Annex II Species & Phocoena (Harbour porpoise) \\
\hline Broad-scale Habitats & Subtidal mixed sediments \\
\hline Broad-scale Habitats & Subtidal mud \\
\hline Broad-scale Habitats & Subtidal sands \\
\hline Broad-scale Habitats & Subtidal sands and gravel \\
\hline FOCl Species & Arctica islandica (Ocean quahog) \\
\hline Habitat & Deep sea sponge aggregations \\
\hline Habitat & Offshore deep sea muds \\
\hline Habitat & Offshore subtidal sands and gravels \\
\hline Other & Waterfowl assemblage \\
\hline
\end{tabular}


Table 11: Application of the 10-tenets to oil and gas decommissioning.

\begin{tabular}{ll}
\hline Tenet & Relevance to Oil, Gas and Offshore Windfarm Decommissioning \\
\hline Ecologically sustainable & $\begin{array}{l}\text { Effects of loss or gain of habitats and surfaces; changes in ecological } \\
\text { equilibrium; increase or removal of pressures }\end{array}$ \\
\hline Technologically feasible & Are there the techniques and technologies for removal? \\
\hline Economically viable & $\begin{array}{l}\text { Costs/benefits/increase/decrease/legacy issues of } \\
\text { energy/GHG/jobs/ecosystem services/societal goods and benefits in } \\
\text { removal and recycling }\end{array}$ \\
\hline Socially desirable/ tolerable & $\begin{array}{l}\text { Societal views of remain/removal and company responsibility; repercussions } \\
\text { for other societal users and uses }\end{array}$ \\
\hline Legally permissible & $\begin{array}{l}\text { Legal requirements to remove or allow retention; challenges to legal } \\
\text { practice }\end{array}$ \\
\hline Administratively achievable & $\begin{array}{l}\text { National bodies to implement international regulations and decide removal } \\
\text { and derogations }\end{array}$ \\
\hline Politically expedient & Politics of austerity, environmental protection and Blue Growth \\
\hline Ethically defensible (morally & Ethics of leaving and/or decommissioning debts for future generations \\
\hline correct) & Influence on indigenous peoples' land and on high seas areas \\
\hline Culturally inclusive & Delivery of relevant and unbiased information \\
\hline Effectively communicable &
\end{tabular}


Table 12: Marine Strategy Framework Directive (MSFD) descriptors and their relevance to oil, gas and offshore windfarm decommissioning.

\begin{tabular}{|c|c|}
\hline MSFD Descriptor & Relevance to Oil, Gas and Offshore Windfarm Decommissioning \\
\hline D01 biodiversity & $\begin{array}{l}\text { Biodiversity/MPA change against uncertain baselines; loss of de facto MPA } \\
\text { with exclusion zone }\end{array}$ \\
\hline D02 alien species & $\begin{array}{l}\text { Surfaces for attachment; increasing the connectivity between oil fields and } \\
\text { spread of alien species }\end{array}$ \\
\hline D03 food webs & Biomass and feeding area changes; reef-effect \& loss \\
\hline D04 seafloor integrity & $\begin{array}{l}\text { Disturbance through drill cuttings, cabling, tunnelling, scour-protection } \\
\text { and surface structures; removal of structures from the seafloor }\end{array}$ \\
\hline D05 fishing & $\begin{array}{l}\text { De facto no-take zones with structures vs. regaining fishing grounds after } \\
\text { removal }\end{array}$ \\
\hline D06 eutrophication & No changes, minimal response \\
\hline D07 hydrography & Removal of impediments to flow, local changes in local hydrodynamics \\
\hline $\begin{array}{l}\text { D08 contamination in } \\
\text { environment }\end{array}$ & $\begin{array}{l}\text { Release of contaminants due to physical disturbance of from anoxic } \\
\text { sediments }\left(\mathrm{H}_{2} \mathrm{~S}, \mathrm{CH}_{4} \text { etc. }\right)\end{array}$ \\
\hline $\begin{array}{l}\text { D09 contamination in } \\
\text { seafood }\end{array}$ & $\begin{array}{l}\text { Uptake of any released contaminants but perhaps dispersion means non- } \\
\text { detectable additional contamination }\end{array}$ \\
\hline D10 litter & $\begin{array}{l}\text { Remaining materials (pipelines, mattresses) regarded as 'litter' with } \\
\text { eventual dispersion into the wider marine environment }\end{array}$ \\
\hline D11 energy/noise & Noise, vibration (use of explosives) and energy use in removal \\
\hline
\end{tabular}




(I)

Questions (Q)

Q1: What oil and gas structure(s) require(s) decommissioning?

Q2: What are the potential decommissioning approaches for the structure?

Q3: What potential decommissioning activities are required?

Q4: What pressures are likely to result from decommissioning activities?

Q5: What MPA features are present within the site?

Q6: What is the potential loss or damage to the designated features?

Q7: What is the potential for the loss or gain of ecosystem services?

Q8: What is the potential for the loss or gain of goods/benefits?
Resources (R)

R1: Inventory of available decommissioning options (\#3)

R2: Activities-Pressures matrix for decommissioning (\#2)

R3: Inventory of protected feature in UK marine waters (\#1)

R4: Assessment of feature sensitivities to Pressures (\#1)

R5: Intermediate ecosystem services (IES) - MPA matrix (\#1)

R6: Goods/Benefits (G/B) - MPA matrix (\#1)

R7: Underlying scientific evidence relating to decommissioning in the

marine environment (\#3)

Figure 1: The Decision Support Framework. 


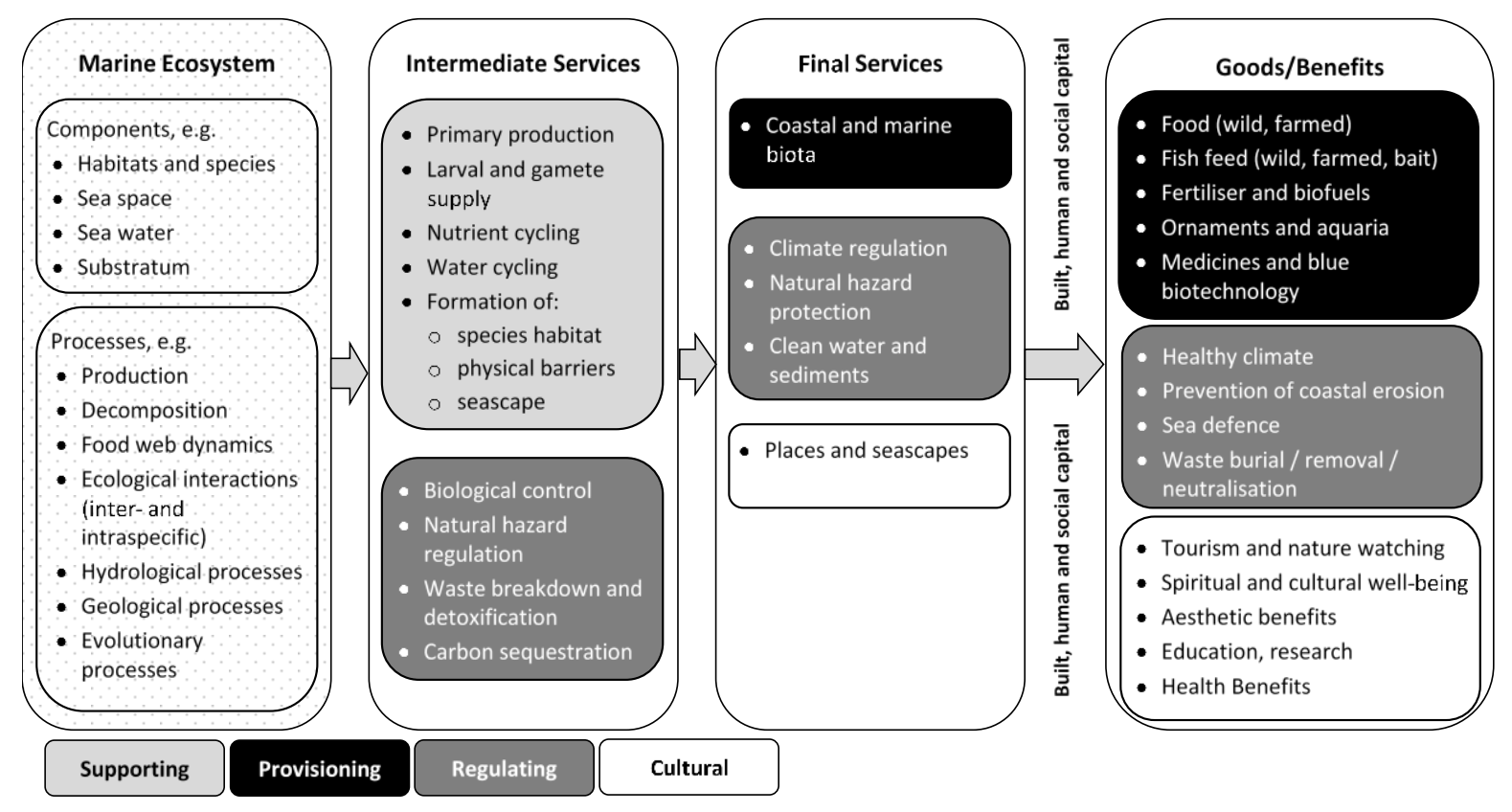

Figure 2: Ecosystem service classification for the marine environment (after Turner et al., 2015). 


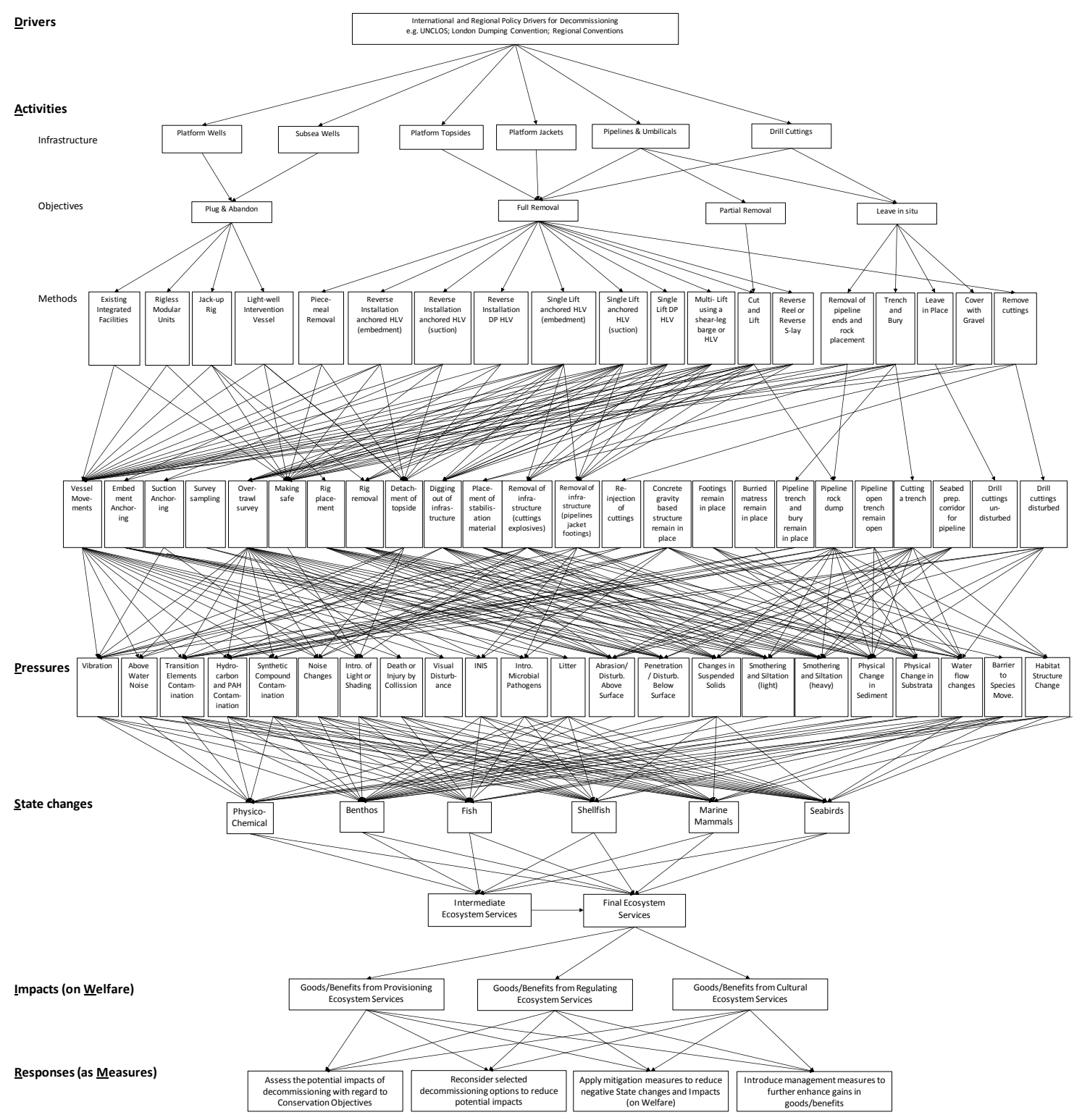

Figure 3: Application of DAPSI(W)R(M) to decommissioning oil and gas structures in MPAs. 


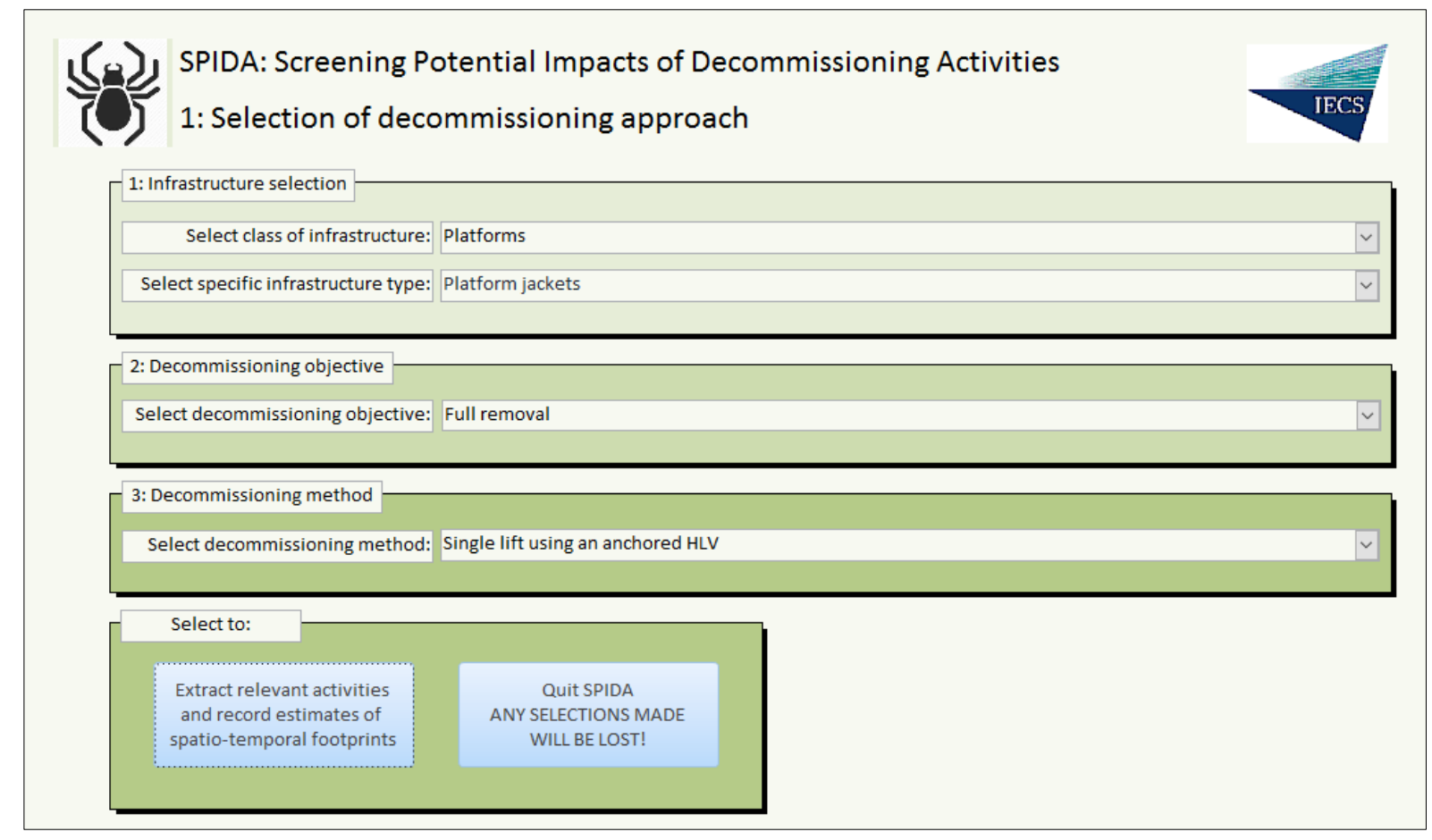

Figure 4: SPIDA's initial user-friendly interface. 


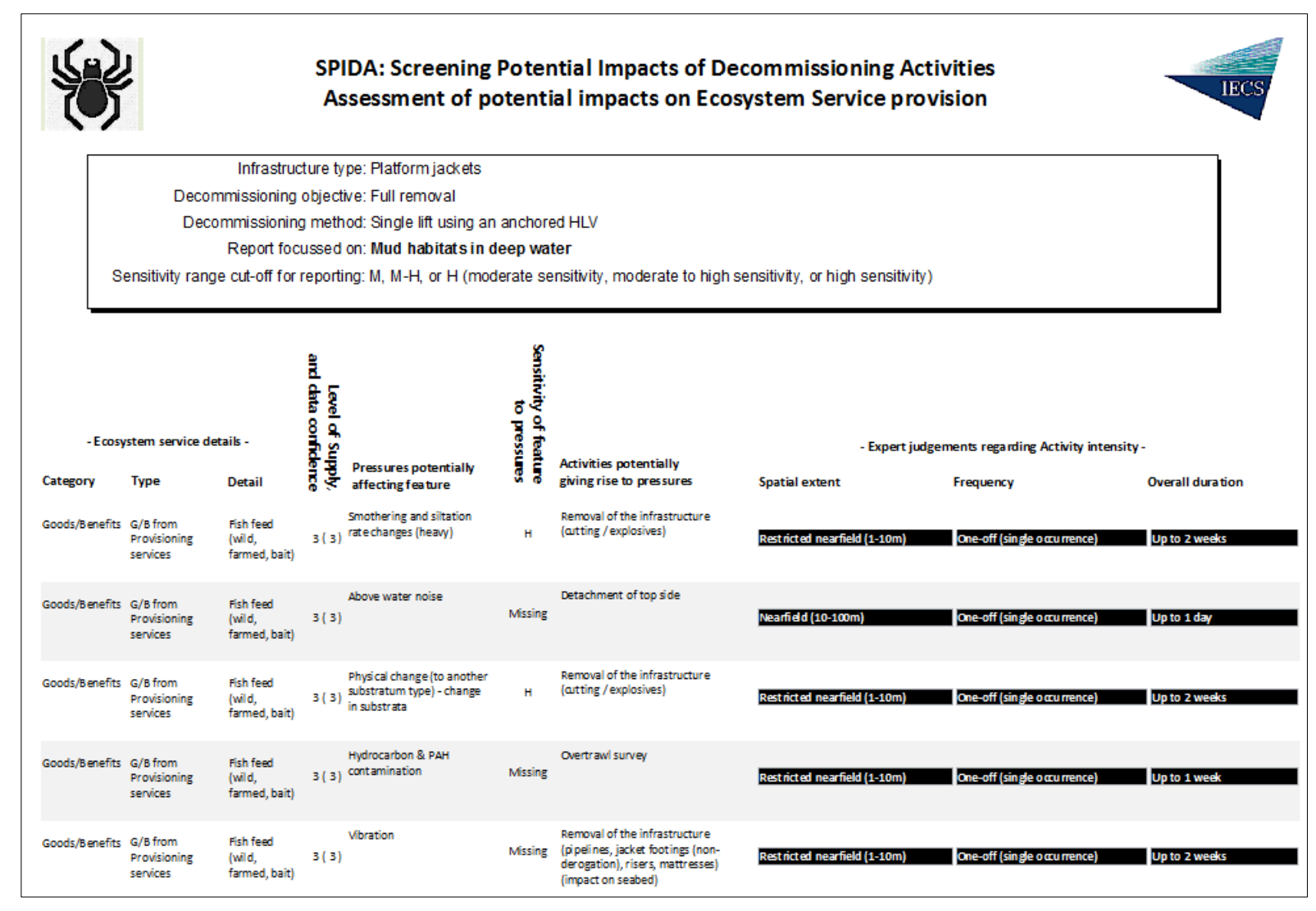

Figure 5: Example of a standardised output from SPIDA. 